\title{
Metodologia de avaliação da distribuição das plantas de milho no campo versus massa de grãos
}

\author{
Evaluation method of corn distribution in the field and grain \\ mass per ear
}

Vilson Antonio Klein ${ }^{1,2}$, Claudia Klein ${ }^{1,3 *}$

'Universidade de Passo Fundo (UPF), BR 285, São Josē, CEP 99052-900, Passo Fundo, RS, Brasil

${ }^{2}$ Bolsista produtividade em Pesquisa $\mathrm{CNPq}$

${ }^{3}$ Bolsista Fapergs/Capes

*autor correspondente

\klein811@hotmail.com
RESUMO: Há controvérsia se o arranjo de plantas de milho no campo realmente afeta o rendimento de grãos. Várias metodologias têm sido usadas para avaliar a eficiência das semeadoras na distribuição das sementes. Para detectar o efeito desse arranjo de plantas de forma pontual, determinaram-se os espaçamentos entre 1.115 plantas e a colheita e pesagem individual dos grãos por planta. A metodologia foi desenvolvida considerando-se os espaçamentos em ambos os lados (direito e esquerdo) das plantas e sua relação com a massa de grãos. Resultados demonstraram que a metodologia, considerando um único espaçamento, tem seus resultados afetados pelo sentido da avaliação na linha. A metodologia considerando as categorias baseadas nos espaçamentos de ambos os lados da planta mostrou-se adequada e demonstrou que apenas as plantas que apresentavam espaçamentos falhos em ambos os lados obtiveram maior massa de grãos por espiga, ocorram com baixa frequência $(1,1 \%)$. A semeadora com dosador de sementes de discos alveolados proporcionou mais de $80 \%$ de espaçamentos aceitáveis. Correlacionando rendimento de grãos nas parcelas com as frequências de ocorrência das categorias de espaçamento não foi detectada significância. Conclui-se que o arranjo de plantas não afeta a massa de grãos por espiga e a estimativa de rendimento de grãos de milho.

PALAVRAS-CHAVE: Arranjo de plantas, espaçamento, semeadura de precisão, Zea mays.

\begin{abstract}
There is considerable controversy on whether the arrangement of corn plants in the field really affects the grain yield. Several methodologies have been used to evaluate the efficiency of seeding and seed distribution. We used the spacing between plants (1115) and crop individual weighing grains per ear to detect the exact effect of plant arrangement. The method considers the spacing on both sides of the plants, and its relationship with grain weight. The results show that spacing affects the method when considering only the direction. The methodology considering categories based on two spacings was robust and demonstrated low frequency (1\%) of plants that lacked spacing on both sides and had higher grain weight per ear. The seeder with a horizontal plate distribution mechanism provided more than $80 \%$ of acceptable spacing. We found no significance between grain yield and the frequencies of occurrences of the categories of spacing. We conclude that the arrangement of plants does not affect the grain weight per ear and the estimated corn yield.
\end{abstract}

KEYWORDS: Arrangement of plants, spacing, precision drilling, Zea mays.

\section{Introdução}

A densidade ideal de semeadura associada ao melhor arranjo de plantas e ao manejo da adubação estão entre as práticas agronômicas recomendadas para a obtenção de maior produtividade de milho (STRIEDER et al., 2007; SANTOS et al., 2011). Segundo Rizzardi, Boller e Dalloglio (1994), o melhor arranjo populacional de plantas é aquele que oferece uma 
distribuição mais uniforme das plantas na linha de semeadura, possibilitando melhor utilização dos fatores de crescimento das plantas, como luz, água e nutrientes.

Para Almeida e Sangoi (1996), a adequada distribuição de plantas é uma das práticas culturais mais importantes para determinar o rendimento de grãos na cultura do milho, pois o estande populacional afeta a arquitetura das plantas, altera o crescimento e o desenvolvimento e influencia na produção, além da partição de fotoassimilados.

Em contraponto, Liu et al. (2004), avaliando estatura de plantas, número de folhas, massa seca e rendimento de grãos, concluíram que essas variáveis não foram afetadas significativamente pelo espaçamento entre as plantas de milho. Os autores afirmam que a variabilidade do espaçamento entre as plantas de milho não afeta o rendimento de grãos, contestando a teoria proposta por Duncan (1984), de que as plantas de milho têm seu desenvolvimento afetado pelas plantas vizinhas, sugerindo espaçamento o equidistante entre elas.

Existem várias metodologias para a avaliação da distribuição das plantas no campo. Liu et al. (2004) utilizaram o desvio padrão dos espaçamentos, destacando que o melhor desempenho que semeadoras-adubadoras conseguem obter no campo é um desvio padrão entre 5 e $7 \mathrm{~cm}$. Na Associação Brasileira de Normas Técnicas tramita projeto de norma regulando os ensaios de semeadora o qual, segundo Coelho (1996), apresenta três categorias baseadas no espaçamento de referência (Xref): espaçamentos aceitáveis (Xi), aqueles com intervalo de tolerância 0,5 Xref $<\mathrm{Xi}<1,5 \mathrm{Xref}$; espaçamentos duplos, $<0,5$ Xref; e espaçamentos falhos, $>1,5$ Xref.

Estudos têm demonstrado que a densidade populacional (plantas ha ${ }^{-1}$ ) é mais importante para a definição do rendimento de grãos do que o arranjo espacial de plantas (KVITSCHAL et al., 2010). Ao passo que Pereira et al. (2008) afirmam que a redução de espaçamento ou o aumento do número de plantas, isoladamente, não promovem o incremento no rendimento de grãos, mas quando aplicadas em conjunto, sim.

As semeadoras-adubadoras desenvolvidas para a semeadura do milho são basicamente equipadas com um dos três tipos de mecanismos dosadores de sementes: (1) os discos perfurados horizontais; (2) dedos prensores; (3) discos verticais pneumáticos, tendo, segundo Coelho (1996), requisitos mínimos para a certificação de $60 \%, 70 \%$ e $90 \%$ dos espaçamentos aceitáveis e valores máximos de coeficiente de variação de $50 \%, 40 \%$ e $30 \%$, respectivamente. Nesse contexto, é importante considerar que as semeadoras com dispositivos dosadores pneumáticos apresentam custo de aquisição significativamente maior em relação àquelas de discos alveolados e, não raras vezes, apresentam desempenho no campo semelhante a semeadoras dotadas de outros mecanismos mais simples e baratos (SILVEIRA et al., 2005).

Assim, este estudo se justifica, pois há controvérsias se o arranjo de plantas de milho afeta o rendimento de grãos. Portanto, a hipótese formulada é que, na presença de espaçamentos falhos, a competição entre plantas é menor, aumentando o incremento na massa de grãos por espiga.

O objetivo deste trabalho foi avaliar o desempenho de uma semeadora-adubadora de discos alveolados e analisar metodologia de avaliação da distribuição das plantas de milho no campo e a sua relação com a massa de grãos por espiga.

\section{Material e Métodos}

O experimento foi conduzido no município de Passo Fundo, RS, altitude média de $700 \mathrm{~m}$ e clima subtropical chuvoso, segundo Köeppen. A precipitação pluvial durante o ciclo do milho foi de $714 \mathrm{~mm}$ regularmente distribuídos, sem ocorrência de deficiência hídrica.

O milho foi semeado $(01 / 10 / 10)$ utilizando-se uma semeadora adubadora modelo PDM Plus 700, em semeadura direta, operada a velocidade de $5 \mathrm{~km} / \mathrm{h}$, equipamento dotado de mecanismo dosador de sementes do tipo discos alveolados, considerado por Coelho (1996) o menos eficiente, e mecanismo sulcador composto por disco de corte, haste sulcadora para incorporação de adubo e disco duplo desencontrado para a semente. A distância entre as linhas foi de $0,9 \mathrm{~m}$ e a semeadora, regulada para dosar seis sementes por metro linear, sendo o espaçamento Xref $=16,67 \mathrm{~cm}$. Não houve qualquer tipo de ajuste de espaçamento e população de plantas. A cultura do milho foi conduzida durante todo o ciclo, seguindo as recomendações técnicas vigentes (RIO GRANDE DO SUL, 2011).

No campo determinou-se a distância entre essas plantas de milho e colheram-se de forma manual (22/2/2011) e individual as espigas $(n=1.115)$ de 6 metros de duas linhas centrais das parcelas (16). Não se constatou ocorrência de mais de uma espiga por planta. Essas foram debulhadas de forma individual e a massa de grãos corrigida para $13 \%$ de umidade.

A metodologia tradicional para a avaliação do desempenho de semeadoras e suas variações é baseada nos espaçamentos entre as plantas e classifica os espaçamentos em aceitáveis, falhos ou duplos e suas combinações possíveis. Além disso, considerando-se que as plantas possuem na linha dois espaçamentos (um de cada lado) e essas combinações interferem potencialmente no desenvolvimento das plantas e seu rendimento em grãos, criaram-se seis categorias que resultaram da combinação dos espaçamentos aceitável, falho e duplo (Tabela 1). Em todos os casos desconsiderou-se a primeira e a última planta de cada linha.

Delineamento experimental casualizado, sendo as 16 parcelas as repetições. Os resultados foram analisados determinando-se a diferença mínima significativa entre espaçamentos ou categorias calculada pelo teste Tukey $5 \%$.

\section{Resultados e Discussão}

A análise de variância indicou diferenças significativas $(p<0,05)$ entre as metodologias avaliadas no que se refere à classificação dos espaçamentos (Tabela 2). Os resultados da metodologia utilizando 0,5 Xref $<\mathrm{Xi}<1,5 \mathrm{Xref}(\mathrm{ABNT})$ proporcionou maior percentual de espaçamentos aceitáveis $(81,0 \%)$ e menores percentuais de espaçamentos falhos e duplos, os quais foram de $11,0 \%$ e $8,0 \%$, respectivamente. Ao passo que a metodologia $0,8 \mathrm{Xref}<\mathrm{Xi}<1,2 \mathrm{Xref}$ proporcionou menor percentual de espaçamentos aceitáveis $(43,5 \%)$ e, por conseguinte, maiores percentuais de espaçamentos falhos (27\%) e duplos $(29,2 \%)$, como era de se esperar, uma vez que 
Tabela 1. Espaçamento entre plantas de milho classificado com três diferentes metodologias e agrupados por categoria de espaçamento entre plantas dentro da linha de plantio.

\begin{tabular}{|c|c|c|c|}
\hline \multirow[t]{2}{*}{ Espaçamentos } & $\begin{array}{c}\text { Média } \\
\pm \text { desvio padrão }\end{array}$ & $\begin{array}{c}{\text { (1) } X \text { ref }^{1}}^{1} \\
0,5 \text { Xref }<X i<1,5 \text { Xref }\end{array}$ & $\begin{array}{c}\text { (2) } \mathrm{X}^{\text {ref }^{1}} \\
0,8 \text { Xref }<\mathrm{Xi}<1,2 \text { Xref }\end{array}$ \\
\hline & \multicolumn{3}{|c|}{ Espaçamento entre plantas (cm) } \\
\hline Aceitáveis & $17,39 \pm 7,51$ & $16,67 \pm 8,33$ & $16,67 \pm 3,34$ \\
\hline Falhos & $>24,90$ & $>25,00$ & $>20,01$ \\
\hline Duplos & $<9,88$ & $<8,33$ & $<13,33$ \\
\hline Espaçamento 1 & \multicolumn{2}{|c|}{ Espaçamento 2} & Categoria \\
\hline Aceitável & \multicolumn{2}{|c|}{ Aceitável } & 1 \\
\hline Falho & \multicolumn{2}{|c|}{ Falho } & 2 \\
\hline Duplo & \multicolumn{2}{|c|}{ Duplo } & 3 \\
\hline Falho & \multicolumn{2}{|c|}{ Aceitável } & 4 \\
\hline Duplo & \multicolumn{2}{|c|}{ Aceitável } & 5 \\
\hline Falho & \multicolumn{2}{|c|}{ Duplo } & 6 \\
\hline
\end{tabular}

${ }^{1}$ Método ABNT (1989); ${ }^{2}$ Método proposto por Silveira et al. (2005); Xref: Espaçamento referência; Xi: Espaçamento aceitável.

Tabela 2. Número de ocorrências com diferentes metodologias e produção de massa de grãos por espiga (g).

\begin{tabular}{cccc}
\hline Espaçamentos & Média \pm DP & 0,5 Xref $<$ Xi $<1,5$ Xref & 0,8 Xref $<$ Xi $<1,2$ Xref \\
\hline Aceitáveis & $\mathbf{8 0 6}(76,5 \%)$ & $867(81 \%)$ & $459(43,5 \%)$ \\
Falhos & $133(12,6 \%)$ & $115(11 \%)$ & $284(27,0 \%)$ \\
Duplos & $115(10,9 \%)$ & $85(8 \%)$ & $312(29,2 \%)$ \\
\hline \multirow{2}{*}{ Espaçamentos } & Média \pm DP & 0,5 Xref $<$ Xi $<1,5$ Xref & 0,8 Xref $<$ Xi $<1,2$ Xref \\
\hline \cline { 2 - 4 } & & Produção de massa grãos por espiga $($ g) & 195,51 b \\
\hline Aceitáveis & 194,07 b & 193,10 b & 203,02 a \\
Falhos & 211,85 a & 211,85 a & 190,88 b \\
Duplos & 188,95 b & 188,95 b & 20,74 \\
\hline CV(\%) & 20,65 & 21,31 & \\
\hline
\end{tabular}

Médias seguidas pela mesma letra na vertical não diferem pelo teste de Tukey $5 \%$ de probabilidade. Xref: espaçamento referência; Xi: espaçamento aceitável; CV: Coeficiente de variação.

o intervalo para os espaçamentos serem considerados aceitáveis é mais estreito. Também pode ser observado na Tabela 1 que a adoção da amplitude $(0,5: 1,5)$ proporcionou um incremento de $5 \%$ de espaçamentos aceitáveis em relação a média $\pm \mathrm{dp}$, enquanto a adoção da amplitude $(0,8: 1,2)$ conduziu à redução de $33 \%$ de espaçamentos aceitáveis.

A semeadora-adubadora equipada com mecanismo dosador de sementes do tipo disco alveolado apresentou desempenho muito bom, pois, de acordo com Coelho (1996), esse tipo de semeadora para ser certificada necessita proporcionar, no mínimo, 60\% dos espaçamentos aceitáveis e CV inferior a 50\%. Assim, a semeadora utilizada neste trabalho pela metodologia da ABNT (1989) proporcionou mais de $80 \%$ de espaçamentos aceitáveis e $\mathrm{CV}=21 \%$, apresentando desempenho superior àqueles requisitos mínimos para semeadoras de dedos prensores, demonstrando mais uma vez que esse tipo de equipamento atende aos requisitos técnicos para uma adequada implantação da cultura do milho com um custo de aquisição menor.

A questão do efeito da velocidade de operação no desempenho das semeadoras precisa ser abordada. Neste sentido, Silva,
Kluthcouski e Silveira (2000) demonstram a redução no número de plantas por metro linear de sulco em função do aumento da velocidade. Esse é um efeito esperado, no entanto é preciso destacar que a regulagem da semeadora deve ser realizada na velocidade de operação, podendo esse efeito ser minimizado, uma vez que, com o aumento da velocidade, a inércia do movimento da máquina tende a dificultar a penetração dos mecanismos sulcadores, mas um ajuste nas rodas limitadoras para essa condição deve minimizar esse efeito.

Independentemente da metodologia, o espaçamento entre plantas afetou a massa de grãos por espiga $(\mathrm{P}<0,05)$, porém não houve diferença significativa $(\mathrm{P}>0,05)$ entre as metodologias avaliadas (Tabela 2). As maiores produções de massa de grãos por espiga foram obtidas para os espaçamentos falhos, enquanto nos espaçamentos aceitáveis e duplos não foram observadas diferenças na produção de massa de grãos por espiga. Esses resultados concordam em parte com a teoria de Duncan (1984), no sentido de que as plantas de milho precisam ter um espaço equidistante, uma vez que o seu desenvolvimento pode ser afetado pelas plantas vizinhas. 
Considerando que o sentido de avaliação pode interferir na classificação dos espaçamentos e, por conseguinte, nos respectivos rendimentos de grãos, e utilizando-se a metodologia da ABNT (0,5 Xref $<\mathrm{Xi}<1,5 \mathrm{Xref}$ ) (Tabela 3$)$, observa-se que no sentido de avaliação $X$ para $Y$ a massa de grãos por espiga nos espaçamento falho foi significativamente maior do que nas classes de espaçamentos aceitáveis e duplos. Quando esse sentido foi invertido não houve mais diferenças significativas entre as classes $(P>0,05)$. Esse resultado provavelmente explica a pouca robustez dessa metodologia para avaliar as reais condições a que as plantas estão submetidas no campo e a sua relação negativa com o rendimento de grãos de milho.

A alteração do número (n) de observações para cada classe é atribuída ao descarte da primeira leitura de espaçamentos. Para os dois sentidos de avaliação constata-se uma manutenção do número de espaçamentos falhos, uma redução nos espaçamentos aceitáveis e aumento no número de espaçamentos duplos.

Aplicando-se a metodologia de dois espaçamentos, as seis categorias de espaçamentos que resultam da combinação dos espaçamentos aceitável, falho e duplo (Tabela 1), elimina-se o efeito do sentido da avaliação na linha e constata-se que para todas as metodologias mais de $50 \%$ das plantas possuíam ambos os espaçamentos aceitáveis (Tabela 4). Na sequência, com maior número de ocorrências, ficou a categoria com um espaçamento aceitável e outro falho e, em terceiro lugar, a categoria com um espaçamento aceitável e outro duplo.
Da análise desses dados é possível constatar a aleatoriedade com que as sementes são depositadas no solo. Supondo-se que as sementes fossem depositadas no espaçamento referência, quando houvesse um espaçamento duplo e a semente seguinte fosse depositada no lugar correto, teríamos então um espaçamento falho. O elevado número de ocorrência de categorias "falho-aceitável" e "duplo-aceitável" comprova que a deposição final das sementes, mesmo que a dosagem pelo mecanismo dosador ocorra de forma perfeita, é afetada de forma aleatória por outros fatores, como a condução da semente ou a própria deposição no sulco.

Com esta metodologia é possível avaliar de fato a planta de forma individualizada. Quando experimentos são feitos com arranjos distintos e as plantas não são avaliadas de forma individual, esse efeito não é detectado.

Esses resultados (Tabela 5), de que espaçamentos falhos em ambos os lados aumentam a massa de grãos por espiga, concordam com os de Rizzardi, Boller e Dalloglio (1994), Rizzardi e Pires (1996) e Liu et al. (2004). Esses autores constataram que o rendimento de grãos não é influenciado pela alteração na distribuição de plantas na linha de semeadura, uma vez que a frequência de ocorrência dessa categoria no campo é baixa $(1,1 \%)$.

Na Figura 1 estão apresentados a frequência de ocorrência das categorias por parcela, o rendimento de grãos dessa parcela,

Tabela 3. Massa de grãos de milho por espiga em função das classes de espaçamento entre plantas de milho com avaliação na linha de plantio em dois sentidos.

\begin{tabular}{|c|c|c|c|}
\hline & \multicolumn{3}{|c|}{ Produção de massa de grãos por espiga (g) } \\
\hline & Aceitáveis & Falhos & Duplos \\
\hline & \multicolumn{3}{|c|}{ Determinação de avaliação feita no sentido $X$ para $Y$ da linha de plantio } \\
\hline Número de observações & 867 & 115 & 85 \\
\hline Média & $193,10 \mathrm{~b}$ & 211,85 a & $188,95 \mathrm{~b}$ \\
\hline Amplitude & 352,64 & 233,25 & 193,48 \\
\hline \multirow[t]{2}{*}{ Desvio padrão } & 41,84 & 41,04 & 37,81 \\
\hline & \multicolumn{3}{|c|}{ Determinação de avaliação feita no sentido $Y$ para $X$ da linha de plantio } \\
\hline Número de observações & 835 & 112 & 114 \\
\hline Média & 195,54 a & 198,19 a & 198,27 a \\
\hline Amplitude & 346,21 & 246,24 & 318,17 \\
\hline Desvio padrão & 40,38 & 39,79 & 43,53 \\
\hline
\end{tabular}

Médias seguidas pela mesma letra na horizontal não diferem pelo teste de Tukey $5 \%$ de probabilidade.

Tabela 4. Número de ocorrências e percentual das categorias dos espaçamento entre plantas de milho de acordo com a metodologia estudada.

\begin{tabular}{|c|c|c|c|c|c|c|}
\hline \multirow[b]{2}{*}{ Categorias } & \multicolumn{2}{|c|}{ Média \pm DP } & \multicolumn{2}{|c|}{0,5 Xref $<$ Xi $<1,5$ Xref } & \multicolumn{2}{|c|}{0,8 Xref $<$ Xi $<1,2$ Xref } \\
\hline & $\begin{array}{l}\text { Número de } \\
\text { ocorrências }\end{array}$ & $\%$ & $\begin{array}{l}\text { Número de } \\
\text { ocorrências }\end{array}$ & $\%$ & $\begin{array}{l}\text { Número de } \\
\text { ocorrências }\end{array}$ & $\%$ \\
\hline $1(\mathbf{A}-\mathbf{A})$ & 613 & $\mathbf{5 7 , 9}$ & 670 & 63,4 & 555 & 52,5 \\
\hline $2(F-F)$ & 13 & 1,2 & 12 & 1,1 & 13 & 1,2 \\
\hline $3(\mathrm{D}-\mathrm{D})$ & 10 & 0,9 & 6 & 0,6 & 13 & 1,2 \\
\hline $4(F-A)$ & 181 & 17,1 & 189 & 17,9 & 213 & 20,2 \\
\hline $5(D-A)$ & 180 & 17,0 & 131 & 12,4 & 183 & 17,3 \\
\hline $6(F-D)$ & 61 & 5,8 & 49 & 4,6 & 80 & 7,6 \\
\hline
\end{tabular}

A: Aceitável; F: Falho; D: Duplo. Xref: espaçamento referência; Xi: espaçamento aceitável; CV: Coeficiente de variação. 
Tabela 5. Massa de grãos por espiga em função das categorias de espaçamento para três metodologias estudadas.

\begin{tabular}{|c|c|c|c|}
\hline \multirow{2}{*}{ Categorias } & Média \pm DP & 0,5 Xref $<$ Xi $<1,5$ Xref & 0,8 Xref $<\mathrm{Xi}<1,2$ Xref \\
\hline & \multicolumn{3}{|c|}{ Massa de grãos por espiga (g) } \\
\hline $1(\mathrm{~A}-\mathrm{A})$ & $189,8 \mathrm{~b}$ & $191,3 \mathrm{~b}$ & $191,5 \mathrm{~b}$ \\
\hline $2(F-F)$ & 241,1 a & 250,1 a & 226,7 a \\
\hline $3(\mathrm{D}-\mathrm{D})$ & 177,8 b & $189,3 \mathrm{~b}$ & $176,9 \mathrm{~b}$ \\
\hline $4(F-A)$ & 210,2 ab & 203,0 b & 201,6 ab \\
\hline $5(D-A)$ & 187,6 b & 190,4 b & 193,0 b \\
\hline $6(F-D)$ & 204,1b & 199,7 b & $196,5 \mathrm{ab}$ \\
\hline CV (\%) & 20,71 & 20,97 & 20,93 \\
\hline
\end{tabular}

Médias seguidas pela mesma letra na vertical não diferem pelo teste de Tukey $5 \%$ de probabilidade. A: Aceitável; F: Falho; D: Duplo. Xref: espaçamento referência; Xi: espaçamento aceitável; CV: Coeficiente de variação.

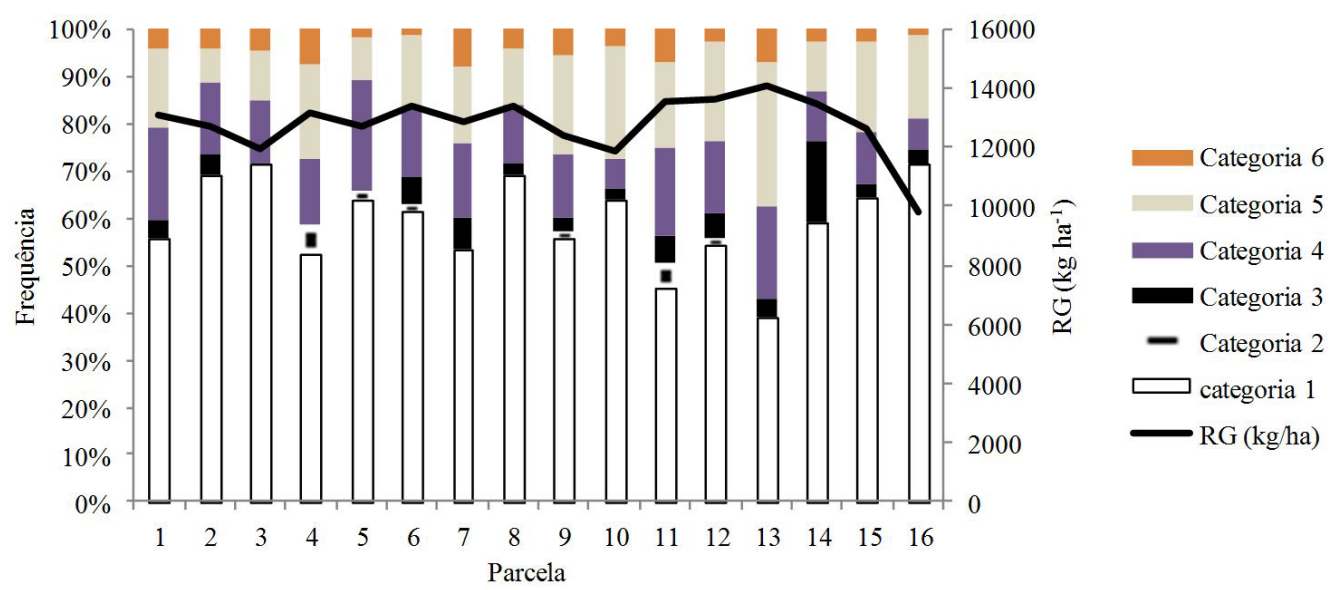

Figura 1. Frequência de ocorrência das categorias e rendimento de grãos $(\mathrm{RG})$ por parcela.

calculado a partir da massa média de grãos por espiga, e o espaçamento referência adotado.

Analisando-se essa figura e também os coeficientes de correlação entre a frequência de ocorrência em cada uma das categorias por parcela e o rendimento de grãos da respectiva parcela $\left(\mathrm{R}^{2}=0,32 ; 0,07 ; 0,10 ; 0,42 ; 0,02\right.$; e 0,14 , para as categorias $1,2,3,4,5$ e 6 , respectivamente), constata-se que o arranjo de plantas não afetou efetivamente a massa de grãos por espiga e, por conseguinte, a estimativa de rendimento de grãos de milho.

\section{Conclusão}

Espaçamentos falhos em ambos os lados da planta de milho aumentam a massa de grãos produzida por espiga, enquanto as demais combinações de espaçamento não afetam a massa de grãos produzida por espiga.

A adoção da metodologia de considerar os espaçamentos em ambos os lados entre as plantas na linha é mais robusta e não foi afetada pelo sentido da avaliação.

A semeadora-adubadora de discos alveolados proporciona mais de $80 \%$ de espaçamentos aceitáveis no plantio mecanizado do milho, apresentando desempenho superior aos requisitos mínimos exigidos para sua certificação.

\section{Referências}

ALMEIDA, M. L.; SANGOI, L. Aumento da densidade de plantas de milho para regiões de curta estação estival de crescimento. Pesquisa Agropecuária Gaúcha, Porto Alegre, v. 2, n. 2, p. 179-183, 1996. ASSOCIAÇÃO BRASILEIRA DE NORMAS TÉCNICAS - ABNT. Semeadora e precisão: ensaio de laboratório/método de ensaio, projeto de norma 12:02.06-004. Rio de Janeiro, 1989. 21 p.

COELHO, J. L. D. Ensaio e certificação das máquinas para semeadoura. In: MIALHE, L. G. Máquinas agrícolas: ensaios e certificação. Piracicaba: Fealq, 1996. cap. 11. p. 551-570.

DUNCAN, W. G. A theory to explain the relationship between corn population and grain yield. Crop Science, Madison, v. 24, p. 1141-1145, 1984.

KVITSCHAL, M. V. et al. Arranjo de plantas e produção de dois híbridos simples de milho. Revista Ciência Agronômica, Fortaleza, v. 41, n. 1, p. 122-131, 2010.

LIU, W. et al. Within-row plant pacing variability does not affect corn yield. Agronomy Journal, Madison, v. 96, p. 275-280, 2004.

PEREIRA, F. R. S. et al. Arranjo espacial de plantas de milho em sistema de plantio direto. Revista Brasileira de Engenharia Agrícola e Ambiental, Campina Grande, v. 12, n. 1, p. 69-74, 2008.

RIO GRANDE DO SUL. Governo do Estado. Secretaria da Agricultura, Pecuária e Agronegócio. Fundação Estadual de Pesquisa Agropecuária. Secretaria do Desenvolvimento Rural, Pesca e Cooperativismo. Indicações técnicas para o cultivo do milho e do sorgo no Rio 
Grande do Sul. Organização de RODRIGUES, L. R.; SILVA, P. R. F. Ijuí: FEPAGRO; EMATER/RS, 2011. (Indicações Técnicas).

RIZZARDI, M. A.; BOLLER, W.; DALLOGLIO, R. Distribuição de plantas de milho, na linha de semeadura, e seus efeitos nos componentes de rendimento. Pesquisa Agropecuária Brasileira, Brasília, v. 29, n. 8, p. 1231-1236, 1994.

RIZZARDI, M. A.; PIRES, J. L. Resposta de cultivares de milho à distribuição de plantas na linha, com e sem controle de plantas daninhas. Ciência Rural, Santa Maria, v. 26, n. 1, p. 13-17, 1996.

SANTOS, M. M. et al. Efeito da fonte de nitrogênio e da época de aplicação na cultura do milho, em plantio direto, com espaçamento reduzido. Revista Brasileira de Milho e Sorgo, Sete Lagoas, v. 10, n. 1, p. 29-37, 2011.
SILVA, J. G.; KLUTHCOUSKI, J.; SILVEIRA, P. M. Desempenho de uma semeadora adubadora no estabelecimento e na produtividade da cultura do milho sob plantio direto. Scientia Agrícola, Piracicaba, v. 57, n. 1, p. $7-12,2000$.

SILVEIRA, J. C. M. et al. Uniformidade de distribuição de plantas e estande de milho (Zea mays L.) em função do mecanismo dosador de sementes. Acta Scientiarum Agronomy, Maringá, v. 27, n. 3 , p. 467-472, 2005.

STRIEDER, M. L. et al. A resposta do milho irrigado ao espaçamento entrelinhas depende do híbrido e da densidade de plantas. Ciência Rural, Santa Maria, v. 37, p. 634-642, 2007. 